\title{
Treatment Outcome of Low-dose Interleukin-2 Therapy in Patients with Metastatic Renal Cell Carcinoma
}

\author{
YUTA TAKEZAWA $^{1}$, KOUJI IZUMI $^{1}$, YUSUKE SHIMURA ${ }^{2}$, MAOLAKE AERKEN $^{1}$, \\ ARIUNBOLD NATSAGDORJI ${ }^{1}$, MASASHI IIJIMA ${ }^{1}$, KAZUYOSHI SHIGEHARA ${ }^{1}$, \\ TAKAHIRO NOHARA ${ }^{1}$, KAZUTAKA NARIMOTO ${ }^{1}$, YOSHIFUMI KADONO ${ }^{1}$, \\ YASUHIDE KITAGAWA ${ }^{1}$, HIROYUKI KONAKA ${ }^{1}$ and ATSUSHI MIZOKAMI ${ }^{1}$ \\ ${ }^{1}$ Department of Integrative Cancer Therapy and Urology, \\ Kanazawa University Graduate School of Medical Science, Kanazawa, Japan; \\ ${ }^{2}$ Department of Hospital Pharmacy, Kanazawa University Hospital, Kanazawa, Japan
}

\begin{abstract}
Renal cell carcinoma $(R C C)$ is one of the most fatal urological malignancies. Approximately $30 \%$ of patients with RCC have metastasis at initial diagnosis and another $30 \%$ have metastasis after radical nephrectomy. Immunotherapy using interferon- $\alpha(I F N-\alpha)$ and interleukin2 (IL-2) has been the main treatment for metastatic RCC $(m R C C)$ patients, with this therapy being still occasionally recommended. The aims of this study were to evaluate the efficacy of low-dose IL-2 and to investigate the prognosis of the patients. Study subjects included 37 patients who were clinically diagnosed with $m R C C$ and received low-dose $I L-$ 2 therapy between December 1999 and October 2014. We investigated the relationship between prognosis and clinical features. The median overall survival (OS), that was calculated from the first use of cytokine therapy, was 19.8 months, while the median progression-free survival (PFS) was 3.82 months. PFS was prolonged in patients who received IL-2 as first-line therapy or second-line therapy following IFN- $\alpha$ therapy. IL-2 therapy should be used as a first- or second-line therapy following IFN- $\alpha$ therapy. IL-2 may have a lower response if it is used after moleculartargeted therapy or other treatments.
\end{abstract}

In the USA, kidney cancer is the 7th most commonly diagnosed cancer in men and the 10th in women (1). In Europe, approximately 88,000 individuals (9th for all cancers)

Correspondence to: Kouji Izumi, Department of Integrative Cancer Therapy and Urology, Kanazawa University Graduate School of Medical Science, 13-1 Takara-machi, Kanazawa, Ishikawa 9208641, Japan. Tel: +81 762652393, Fax: +81 762344263, e-mail: azuizu2003@yahoo.co.jp

Key Words: Interleukin-2, immunotherapy, metastatic renal cell carcinoma, progression-free survival. were diagnosed with kidney cancer in 2008 (2). Renal cell carcinoma (RCC) is the most dominant histological phenotype of kidney cancer. A total of $20-40 \%$ of RCC patients have recurrent metastatic disease after primary nephrectomy; therefore, approximately 50\% of all patients who are diagnosed with RCC should receive systemic therapy during the course of their disease (3). In recent years, moleculartargeted agents, such as tyrosine kinase inhibitors (TKIs), against metastatic RCC (mRCC) have been intensively investigated and the treatment of $\mathrm{mRCC}$ has shifted toward them. Before the era of TKIs, immunotherapy, such as interferon- $\alpha(\mathrm{IFN}-\alpha)$ and interleukin-2 (IL-2), played a central role in $\mathrm{mRCC}$ treatment; however, recently, immunotherapy is seldom used for the treatment of mRCC worldwide. Immunotherapy is still occasionally recommended for patients who are concerned about the severe side-effects of moleculartargeted agents that include hypertension, thrombocytopenia, cardiac hypofunction and hypothyroidism (4). A retrospective study from Japan, in the immunotherapy era, reported that the median survival time was approximately twice that of previous studies from North America or Europe and that immunotherapy might contribute to improved prognosis in mRCC patients (5). Interestingly, the dose of IL-2 used in Japan was much lower than that used in North America or Europe (6). However, the efficacy of low-dose IL-2 therapy has not yet been reported. In the present study, we investigated the treatment course and prognosis of low-dose IL-2 therapy and clarified the specificity of IL-2 usage contributing to improvement in the prognosis of mRCC patients.

\section{Patients and Methods}

Study subjects included 37 patients who were clinically diagnosed with $\mathrm{mRCC}$ and received low-dose IL-2 therapy $\left(7 \times 10^{5}\right.$ or $14 \times 10^{5}$ IU/body, 1-5 times/week) between December 1999 and October 2014. Risk and background factors were dichotomized as follows: age ( $<62$ years $v s . ~ \geq 62$ years), Karnofsky performance status $(\leq 80$ 
vs. >80), previous nephrectomy (yes vs. no), pathological subtype (clear cell carcinoma (CCC) vs. non-CCC), lung metastasis alone (yes $v s$. no), first-line use, including combination with IFN- $\alpha$ therapy or second-line use following IFN- $\alpha$ therapy (yes $v s$. no), and Memorial Sloan Kettering Cancer Center (MSKCC) risk classification (intermediate $v s$. poor) (7).

Overall survival (OS) and progression-free survival (PFS) were calculated from the starting point of prior immunotherapy (IL-2 or IFN- $\alpha$ ) to death or date of last follow-up and from the starting point of IL-2 to disease progression, respectively. We also investigated the relationship between survival and background factors. The KaplanMeier method was used to display survival data. We determined $p$ values using the log-rank test for survival distributions; $p<0.05$ was considered statistically significant. Analyses were performed using the Prism 5 Software (GraphPad Software, San Diego, California, USA, http://www.graphpad.com/).

\section{Results}

Patients' characteristics are presented in Table I. The median age was 62 years (range=26-84). Twenty-eight patients were male and nine female. All patients had metastasis at the starting point of immunotherapy. The median OS was 19.8 months and the median PFS 3.82 months (Figure 1A and B). Twenty-one patients had Karnofsky performance status of $\leq 80(57 \%)$. Thirty-three patients underwent nephrectomy (89\%). Thirty-two patients had CCC (86\%) and five nonCCC (14\%). Seven patients had lung metastasis alone (19\%). A total of 18 patients were classified as MSKCC intermediate risk (49\%) and 19 as poor risk (51\%). Twenty patients were administered IFN- $\alpha$ therapy before IL-2 therapy, six patients were given first-line IL-2 therapy, while four patients were subjected to combination therapy of IFN$\alpha$ and IL-2; therefore, a total of 30 patients were defined as first- or second-line users of IL-2 (Table I). No patient developed side-effects from IL-2 that warranted interruption of treatment.

On univariate analysis of PFS, patients who received firstline IL-2 therapy, including combination with IFN- $\alpha$ therapy or as second-line therapy following IFN- $\alpha$ therapy, had better PFS than those who were administered other sequential treatments (Table II and Figure 2).

\section{Discussion}

Although immunotherapy used to be the main therapy for mRCC, the use of molecular-targeted therapy as first-line therapy has spread. Naito et al. previously reported that firstline immunotherapy, including both IFN- $\alpha$ and IL-2, could improve the prognosis of advanced RCC patients and that patients could undergo immunotherapy without severe sideeffects, whereas molecular-targeted therapy had more adverse events than immunotherapy (5). The study population was 1,463 patients who were clinically diagnosed with $\mathrm{mRCC}$ with an OS of 21.4 months (5). In the present
Table I. Patients' characteristics.

\begin{tabular}{lc}
\hline Clinical factors & $\mathrm{n}$ \\
\hline Age & \\
$<62$ & 17 \\
$\geq 62$ & 20 \\
Gender & \\
Male & 28 \\
Female & 9 \\
Karnofsky-PS & \\
$\leq 80$ & 21 \\
$>80$ & 16 \\
Previous nephrectomy & \\
Yes & 33 \\
No & 4 \\
Subtype & \\
CCC & 32 \\
Non-CCC & 5 \\
Lung metastasis alone & \\
Yes & 7 \\
No & 30 \\
MSKCC risk & \\
Intermediate & 18 \\
Poor & 19 \\
1st or 2nd line use & \\
Yes & 30 \\
No & 7 \\
\hline
\end{tabular}

PS, Performance status; CCC, clear cell carcinoma; MSKCC, Memorial Sloan Kettering Cancer Center.

study, OS was almost identical; however, our study included patients who underwent molecular-targeted therapy after immunotherapy. Our results suggested that low-dose IL-2 therapy should be used as a first-line therapy or as a secondline therapy following IFN- $\alpha$ and not molecular-targeted therapy. A sequential treatment strategy from moleculartargeted therapy to IL-2 therapy may no longer be considered effective.

A previous report showed that molecular-targeted therapy after using immunotherapy prolonged patient survival (8). Our results were consistent with these findings; however, those reports stated that patients who were treated with immunotherapy for long periods without disease progression might have had less aggressive disease than those previously treated with molecular-targeted therapy. It is difficult to investigate the efficacy of immunotherapy in patients with aggressive disease because, in recent times, moleculartargeted therapy has been chosen as first-line therapy in such patients.

There is a question as to whether the small sample size in the present study may have prevented the determination of statistical significance of differences between the groups. We believe that larger prospective studies that will include patients with diverse ethnic backgrounds and longer follow- 


\section{os}

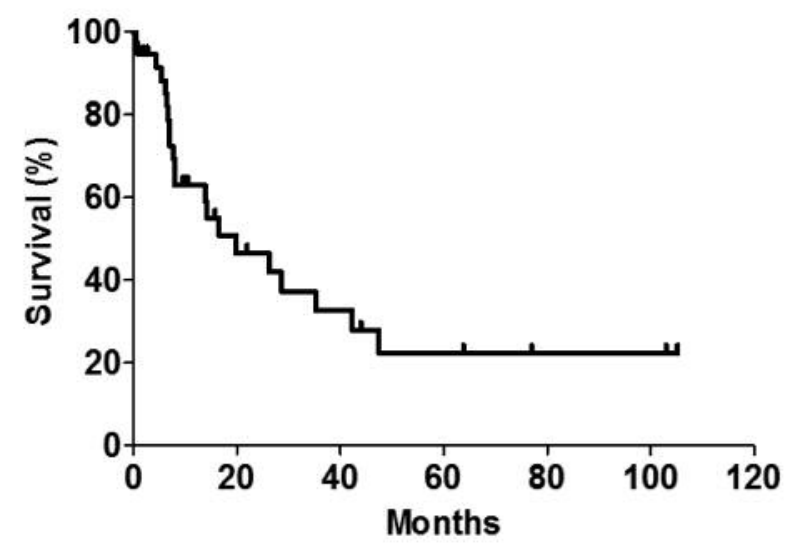

PFS

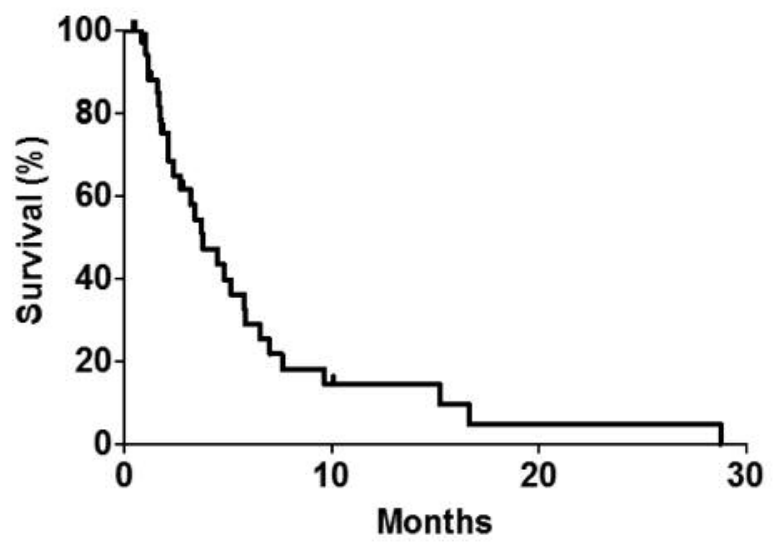

Figure 1. Overall survibal (OS) (A) and progression-free survival (PFS) (B) of 37 patients treated with low-dose IL-2 therapy.

Table II. Univariate analysis for PFS.

\begin{tabular}{|c|c|c|}
\hline Clinical factors & $\begin{array}{c}\text { Median PFS } \\
\text { (months) }\end{array}$ & $p$-Value \\
\hline \multicolumn{3}{|l|}{ Age } \\
\hline 62 & 2.14 & \multirow[t]{2}{*}{0.2209} \\
\hline$\geq 62$ & 4.51 & \\
\hline \multicolumn{3}{|l|}{ Gender } \\
\hline Male & 4.8 & \multirow[t]{2}{*}{0.988} \\
\hline Female & 3.42 & \\
\hline \multicolumn{3}{|l|}{ Karnofsky-PS } \\
\hline$\leq 80$ & 4.8 & \multirow[t]{2}{*}{0.5714} \\
\hline$>80$ & 2.73 & \\
\hline \multicolumn{3}{|c|}{ Previous nephrectomy } \\
\hline Yes & 4.51 & \multirow[t]{2}{*}{0.4602} \\
\hline No & 1.98 & \\
\hline \multicolumn{3}{|l|}{ Subtype } \\
\hline $\mathrm{CCC}$ & 4.46 & \multirow[t]{2}{*}{0.4227} \\
\hline Non-CCC & 3.42 & \\
\hline \multicolumn{3}{|c|}{ Lung metastasis alone } \\
\hline Yes & 9.67 & \multirow[t]{2}{*}{0.1842} \\
\hline No & 3.42 & \\
\hline \multicolumn{3}{|l|}{ MSKCC risk } \\
\hline Intermediate & 3.42 & \multirow[t]{2}{*}{0.7119} \\
\hline Poor & 4.8 & \\
\hline \multicolumn{3}{|c|}{1 st or 2 nd line use } \\
\hline Yes & 4.51 & \multirow[t]{2}{*}{0.0207} \\
\hline No & 2.14 & \\
\hline
\end{tabular}

PFS, Progression-free survival; PS, performance status; CCC, clear cell carcinoma; MSKCC, Memorial Sloan Kettering Cancer Center.

up periods are required to confirm our findings. Moreover, treatment with recently developed immune checkpoint inhibitors may prolong the survival of mRCC patients. It remains to be determined if conventional immunotherapy, such as IFN- $\alpha$ and IL-2, still has an efficacy for the

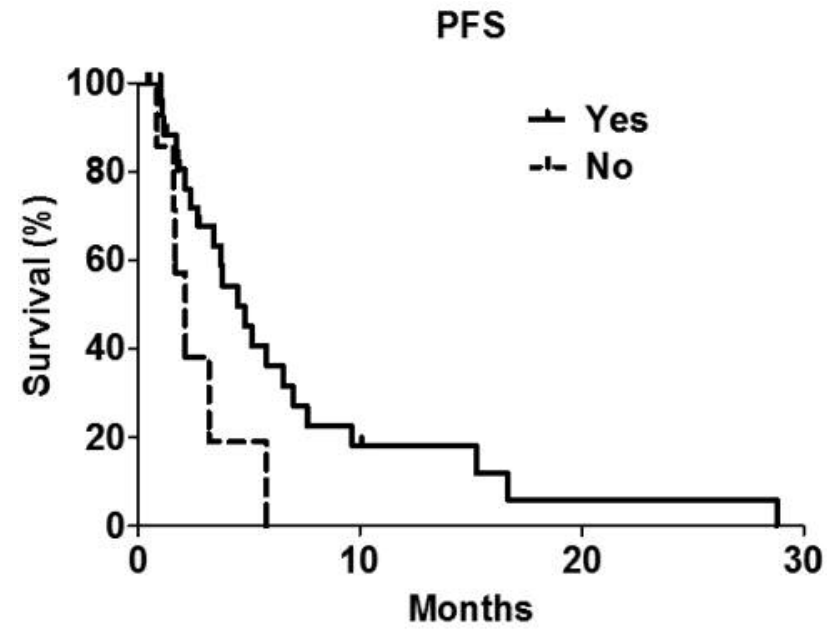

Figure 2. Progression-free survival (PFS) of patients who were dichotomized into two groups: first-line users, including combination with $I F N-\alpha$ therapy, or second-line users following IFN- $\alpha$ therapy (yes vs. no).

improvement of survival because the anti-tumor mechanisms are similar to each other and, perhaps, the effect may be much higher with immune checkpoint inhibitors than conventional immunotherapy.

\section{Conclusion}

The present study showed, for the first time, that low-dose IL-2 therapy should be used as first- or second-line therapy following IFN- $\alpha$, particularly in patients who are concerned about the severe side-effects of molecular-targeted therapy. IL-2 might have a lower response if it is used after molecular-targeted therapy. 


\section{References}

1 Siegel RL, Miller KD and Jemal A: Cancer statistics, 2016. CA Cancer J Clin 66(1): 7-30, 2016.

2 Ferlay J, Parkin DM and Steliarova-Foucher E: Estimates of cancer incidence and mortality in Europe in 2008. Eur J Cancer 46(4): 765-781, 2010.

3 Molina AM and Motzer RJ: Current algorithms and prognostic factors in the treatment of metastatic renal cell carcinoma. Clin Genitourin Cancer 6(Suppl 1): S7-13, 2008.

4 Harada K, Miyake H, Kurahashi T and Fujisawa M: Long-term complete response to very-low-dose interleukin-2 therapy in patients with metastatic renal cell carcinoma: report of two cases. Clin Exp Nephrol 15(6): 966-969, 2011.

5 Naito S, Yamamoto N, Takayama T, Muramoto M, Shinohara N, Nishiyama K, Takahashi A, Maruyama R, Saika T, Hoshi S, Nagao K, Yamamoto S, Sugimura I, Uemura H, Koga S, Takahashi M, Ito F, Ozono S, Terachi T, Naito S and Tomita Y: Prognosis of Japanese metastatic renal cell carcinoma patients in the cytokine era: a cooperative group report of 1463 patients. Eur Urol 57(2): 317-325, 2010.
6 Akaza H, Tsukamoto T, Onishi T, Miki T, Kinouchi T and Naito $\mathrm{S}$ : A low-dose combination therapy of interleukin-2 and interferon-alpha is effective for lung metastasis of renal cell carcinoma: a multicenter open study. Int J Clin Oncol 11(6): 434-440, 2006.

7 Motzer RJ, Bacik J, Murphy BA, Russo P and Mazumdar M: Interferon-alfa as a comparative treatment for clinical trials of new therapies against advanced renal cell carcinoma. J Clin Oncol 20(1): 289-296, 2002.

8 Escudier B, Michaelson MD, Motzer RJ, Hutson TE, Clark JI, Lim HY, Porfiri E, Zalewski P, Kannourakis G, Staehler M, Tarazi J, Rosbrook B, Cisar L, Hariharan S, Kim S and Rini BI: Axitinib versus sorafenib in advanced renal cell carcinoma: subanalyses by prior therapy from a randomised phase III trial. Br J Cancer 110(12): 2821-2828, 2014.

Received July 13, 2016

Revised July 23, 2016

Accepted August 2, 2016 